\title{
VIABILITAS POLEN CABAI KERITING (CK004) PADA BERBAGAI KOMBINASI PENGERINGAN DAN LAMA PENYIMPANAN
}

Oleh :

\section{DWI RAHMAWATI *) dan PRAYITNO**)}

\begin{abstract}
ABSTRAK
Penelitian ini bertujuan untuk mengetahui viabilitas polen cabai keriting setelah dikeringkan dengan berbagai kombinasi pengeringan dan disimpan selama 6 minggu dalam ultrafreezer dengan suhu $80^{\circ} \mathrm{C}$. Selain itu, diharapkan penelitian ini dapat berguna untuk polinasi buatan dan teknik persilangan tanaman cabai dalam upaya pelestarian dan pembudidayaanya serta untuk mengantisipasi persediaan polen yang sedikit. Penelitian dilaksanakan mulai bulan Agustus sampai Desember 2012, bertempat di Laboratorium PT. East West Seed Indonesia, Jember. Metode yang digunakan adalah Rancangan Acak Lengkap dengan 2 perlakuan dan 3 ulangan. Untuk menghitung jumlah polen viable digunakan metode Nyine dan Pillay (2007). Data dianalisis menggunakan ANOVA dengan uji lanjut DMRT. Hasil penelitian menunjukkan bahwa pengeringan polen menggunakan $\mathrm{MgCl}$ menghasilkan kadar air rata-rata $4.67 \%$, sedangkan menggunakan drying beads menghasilkan rata-rata kadar air $6.9 \%$. Uji viabilitas polen, baik untuk penyimpanan 0 minggu maupun penyimpanan 6 minggu, menghasilkan daya kecambah diatas standar minimal daya berkecambah polen berdasarkan ISO PT. Eeast West Seed Indonesia No.SP/07/FPR tanggal 9 Februari 2009 untuk semua krop yaitu 1\%. Daya kecambah polen sebelum disimpan sebesar $2.78-6.04 \%$ dan setelah disimpan 6 minggu sebesar $1.58-4.56 \%$.
\end{abstract}

Kata kunci: Cabai keriting, Kombinasi pengeringan, Lama penyimpanan, Viabilitas polen,

\section{PENDAHULUAN}

Kebutuhan akan komoditas buah cabai khususnya di Indonesia semakin meningkat seiring dengan meningkatnya jumlah penduduk dan berkembangnya industri makanan, obat-obatan serta kosmetika yang memanfaatkannya (Nawangsih et al., 1994). Menurut Ditjen Hortikultura (2009), pada tahun 2002, 2005, dan 2008 pola konsumsi masyarakat Indonesia terhadap cabai mengalami peningkatan yaitu masing-masing sebesar 1.42 $\mathrm{kg} / \mathrm{tahun} / \mathrm{kapita}, \quad 1.51 \mathrm{~kg} / \mathrm{tahun} / \mathrm{kapita}$, dan 1.54 $\mathrm{kg} /$ tahun/kapita. Sedangkan luas daerah penanaman cabai di Indonesia adalah $182.000 \mathrm{Ha}$ dengan ratarata produksi 2,6 ton/ha (BPS, 2008). Pada tahun 2012, produksi benih cabai merah diharapkan sebanyak 1.423 .500 ton (Direktorat Jendral Hortikultura, 2012). Akan tetapi peningkatan produksi cabai tersebut tidak diikuti oleh ketersediaan benih cabai bermutu di Indonesia. Menurut laporan FAO (1995) Indonesia merupakan negara dengan daerah penanaman terluas di dunia, tetapi produktivitasnya masih jauh di bawah ratarata produksi dunia yang mencapai 9,5 ton/ha. Rendahnya produktivitas cabai di Indonesia disebabkan oleh kualitas benih yang masih rendah, teknik budidaya yang diterapkan belum optimal, dan gangguan hama serta penyakit (Hening, 1999). Untuk itu, salah satu cara meningkatkan produksi dan produktivitasnya adalah dengan penggunaan benih hibrida.

Salah satu bahan yang diperlukan dalam menghasilkan benih hibrida adalah polen. Kontinuitas ketersediaan polen cabai merupakan hal yang penting diperlukan untuk melakukan proses penyerbukan, sehingga polen cabai perlu disimpan terlebih dahulu pada suhu rendah sehingga penyerbukan dapat dilakukan pada waktu yang tepat. Menurut Card (2007), polen merupakan sumber plasma nutfah yang berharga bagi kegiatan perbaikan tanaman. Pengelolaan polen untuk mempertahankan viabilitasnya tetap tinggi merupakan hal yang penting agar fertilisasi yang diharapkan dapat terjadi (Warid, 2009). Kegiatan pengolahan tersebut meliputi ekstrak bunga, pengeringan anther, pengocokan anther, pengeringan polen, dan pengujian viabilitas polen. Dengan demikian, ketersedian polen yang baik diawali dari proses pengeringan anther dan polen yang tepat.

Umumnya, pengeringan anther menggunakan $\mathrm{AC}$ dan pengeringan polen menggunakan $\mathrm{MgCl}_{2}$, namun metode ini dinilai kurang efisien karena penggunaan AC tidak diukur berdasarkan jumlah anther yang akan dikeringkan. Selain itu, jenis AC yang digunakan juga mempengaruhi mutu polen yang dihasilkan. Demikian pula halnya dengan proses pengeringan polen. Jika $\mathrm{MgCl}_{2}$ sudah jenuh akan mencair dan tidak bisa digunakan kembali. 
Dwi Rahmawati dan Prayitno, Viabilitas Polen Cabai Keriting (CK004) Pada Berbagai Kombinasi Pengeringan Dan Lama Penyimpanan

Drying beads diharapkan dapat digunakan untuk mengeringkan anther dan polen tanaman cabai sehingga penggunaan drying beads dapat menghemat biaya karena pengeringan menggunakan drying beads dapat disesuaikan dengan kuantitas anther dan polen yang akan dikeringkan. Selain itu, drying beads dapat diregenerasi berulang-ulang.

Polen merupakan sel hidup yang dapat mengalami kemunduran dan kematian (Widiastuti dan Palupi, 2008). Polen yang telah dikeringkan adakalanya tidak langsung digunakan namun disimpan hingga waktu penyerbukan yang tepat. Lama simpan polen dapat ditingkatkan dengan mengendalikan faktor-faktor yang mempengaruhi viabilitasnya. Menurut Elgersma et al. (1989), faktor lingkungan seperti suhu dapat mempengaruhi kemampuan berkecambah polen dan pertumbuhan buluh polen.

Tujuan penelitian ini untuk mengetahui viabilitas polen cabai keriting CK-004 setelah dikeringkan dengan berbagai kombinasi pengeringan dan penyimpanan pada waktu berbeda. Sehingga berguna untuk polinasi buatan dan teknik persilangan tanaman cabai dalam upaya pembudidayaannya.

\section{METODOLOGI}

\section{Waktu dan Tempat Penelitian}

Penelitian ini dilaksanakan pada bulan Agustus - Desember 2012. Bunga tanaman cabe keriting diambil dari kebun percobaan PT. EWSI kantor cabang Jember dan pengamatan viabilitas polen dilakukan di laboratorium pollen PT. EWSI kantor cabang Jember.

\section{Alat dan bahan}

Alat dan bahan yang digunakan adalah mikroskop binokuler, kaca objek, kaca penutup, jarum pentul, dan lain-lain, sedangkan bahan yang digunakan terdiri dari bunga tanaman cabe, media perkecambahan, $\mathrm{MgCl}_{2}$, Drying beads, Alkohol, Alumunium foil dan lain-lain.

\section{Pelaksanaan Penelitian}

Pengeringan dan penyimpanan polen dilakukan dengan metode eksperimen, memakai Rancangan Acak Lengkap dengan 2 perlakuan dan 3 ulangan. Untuk menghitung polen viabel dan persentase viabilitas polen digunakan metode Nyine dan Pillay (2007). Data dianalisis menggunakan ANOVA dengan uji lanjut DNMRT.

Penelitian diawali dengan pengambilan bunga dari tandan bunga cabai yang masih berbentuk balon/gelembung. Pengambilan bunga dilakukan pada pagi hari atau sore hari sebelum bunga mekar agar bunga tidak mengalami penyerbukan. Setelah dikumpulkan, bunga dibiarkan semalam untuk menghilangkan getah sehingga memudahkan dalam pengekstrasian.
Ekstraksi bunga dilakukan untuk memisahkan anther dengan bagian bunga yang lain menggunakan ekstraktor yaitu alat ayakan berbentuk kotak dengan ukuran 50 x $50 \mathrm{~cm}$.

Selanjutnya anther hasil ekstraksi dikeringkan menggunakan kombinasi pengeringan seperti perlakuan dan disimpan selama enam minggu. Pengujian viabilitas pollen dengan teknik germinasi yaitu pollen diletakkan pada kaca preparat/deck glass kemudian ditetesi dengan media dan diaduk menggunakan jarum ose. Objek diletakkan dalam wadah Tupperware yang sudah berisi kertas buram lembab. Pollen diinkubasi selama 2 jam. Polen yang viabel ditandai dengan adanya pertumbuhan tabung polen.

\section{Metode Penelitian}

Penelitian dilakukan dengan menggunakan Rancangan Acak Lengkap (RAL) dua faktor. Faktor pertama yang diuji adalah kombinasi pengeringan anther dan pollen $(\mathrm{P})$, yang terdiri atas delapan taraf yaitu Pengeringan anther dengan $\mathrm{AC}$ dan pengeringan pollen dengan $\mathrm{MgCl}_{2}(\mathrm{P} 1)$, Pengeringan anther dengan $\mathrm{AC}$ dan pengeringan pollen dengan Drying beads (P2), Pengeringan anther dengan ACDrying beads dan pengeringan pollen dengan $\mathrm{MgCl}_{2}$ (P3), Pengeringan anther dengan AC-Drying beads dan pengeringan pollen dengan Drying beads (P4), Pengeringan anther dengan Drying beads-AC dan pengeringan pollen dengan $\mathrm{MgCl}_{2}$ (P5), Pengeringan anther dengan Drying beads-AC dan pengeringan pollen dengan Drying beads (P6), Pengeringan anther dengan Drying beads dan pengeringan pollen dengan $\mathrm{MgCl}_{2}$ (P7), Pengeringan anther dengan Drying beads dan pengeringan pollen dengan Drying beads (P8)

Sedangkan faktor kedua adalah lama penyimpanan (T) yang terdiri dari dua taraf yaitu tanpa disimpan (T1) dan disimpan 6 minggu (T2). Dari perlakuan diatas terdapat 16 kombinasi perlakuan yang diulang 3 kali sehingga terdapat 32 satuan percobaan.

Menurut Hanifah (2011), model statistik yang digunakan sebagai berikut :

$\gamma_{i j}=\mu+\alpha_{i}+\beta_{j}+(\alpha \beta)_{i j}+\epsilon_{i j}$

Dimana :

$\gamma_{i j}=$ Respon atau nilai pengamatan dari perlakuan ke-i dan ulangan ke-j

$\mu \quad=$ Nilai tengah umum

$\alpha_{i} \quad=$ Pengaruh perlakuan ke-i (Faktor 1)

$\beta_{j} \quad=$ Pengaruh perlakuan ke-j (Faktor 2)

$(\alpha \beta)_{i j}=$ Pengaruh interaksi taraf ke-i faktor 1 dan taraf ke-j dari faktor 2

$\epsilon_{i j}=$ Pengaruh galat percobaan dari perlakuan taraf ke-i dari faktor 1 dan taraf ke-j dari faktor 2 pada ulangan ke-k 


\section{Parameter Pengamatan}

a. Kadar air (\%)

Pengujian kadar air ini dimaksudkan untuk mengukur penyusutan kadar air yang terjadi. Kadar air pollen yaitu kandungan air yang terdapat dalam pollen. Pengukuran kadar air pollen dilakukan setelah pengeringan polen. Pengukuran kadar air dilakukan dengan metode oven suhu $130^{\circ} \pm 3^{\circ} \mathrm{C}$ selama \pm 1 jam dengan contoh kerja sebanyak $0.25 \mathrm{gr}$ polen. Pengujian kadar air polen dilakukan dengan tujuan untuk mengetahui pengaruh model pengeringan anther dan pengeringan polen terhadap kadar air polen tanaman cabai keriting (Capsicum annuum, L). Menurut Sutopo (1998) penghitungan kadar air pollen dengan menggunakan rumus:

$\% K A=\frac{M 2-M 3}{M 2-M 1} x 100 \%$

Keterangan :

$\% \mathrm{KA}$ : Persentase kadar air polen

M1 : Berat cawan + tutup

M2 : Berat cawan + tutup + polen sebelum di

oven

M3 : Berat cawan + tutup + polen setelah di

oven

\section{b. Viabilitas Polen (\%)}

Persentase viabilitas polen merupakan perbandingan polen yang berkecambah dengan polen yang dikecambahkan. Polen dikecambahkan dengan media EWID pada deck glass dengan jarum ose dan diinkubasi selama \pm 2 jam. Media Ewid merupakan media hasil temuan milik PT. East West Seed Indonesia yang tidak dapat dipublikasikan. Ciri- ciri pollen yang berkecambah yaitu dengan munculnya ekor dan ini dapat dilihat pada mikroskop. Menurut Warid (2009) perhitungan perkecambahan menggunakan rumus:

$\% D B=\frac{\text { Jumlah pollen yang berkecambah }}{\text { Jumlah pollen yang dikecambahkan }}$

Perhitungan viabilitas dilakukan dengan tujuan untuk mengetahui pengaruh kombinasi pengeringan dan lama penyimpanan terhadap viabilitas polen tanaman cabai keriting (Capsicum annuиm, L).

\section{Metode Pengumpulan Data}

Data yang digunakan dalam penelitian ini adalah data primer. Data primer yaitu data yang diperoleh dari hasil percobaan perlakuan kombinasi pengeringan anther dan pollen serta lama

penyimpanan pollen sebagaimana pada rancangan percobaan yang telah dilakukan. Data yang diperoleh merupakan hasil perhitungan persentase polen yang viabel setelah dikecambahkan.

\section{Metode Analisis Data}

Untuk menguji hipotesis yang telah ditetapkan, data yang diperoleh dari percobaan di atas, dilakukan sidik ragam. Apabila terdapat beda nyata, maka dilakukan uji lanjut menggunakan Duncan Multiple Range Test (DMRT) pada taraf $5 \%$.

\section{HASIL DAN PEMBAHASAN \\ Kadar Air Polen}

Salah satu faktor yang mempengaruhi penyimpanan polen ialah kadar air polen. Kadar air merupakan banyaknya air yang terkandung dalam bahan yang dinyatakan dalam persen. Menurut kalibrasi PT.EWID (2012), polen untuk cabai keriting yang telah mengalami proses pengeringan memiliki kadar air $\pm 5,52 \%$. Pengujian ini bertujuan untuk mengetahui perlakuan yang terbaik dalam menghasilkan kadar air yang sesuai sehingga polen bisa disimpan cukup lama dan ketika digunakan kembali polen yang disimpan tersebut masih memiliki viabilitas yang tinggi.

Hasil ANOVA menunjukkan bahwa interkasi dua faktor tidak memberikan pengaruh yang nyata (ns) terhadap kadar air polen. Namun berdasarkan uji DMRT 5\% diketahui bahwa kadar air polen dipengaruhi oleh perlakuan pengeringan polen. Hasil penelitian menunjukkan bahwa perlakuan pengeringan polen dengan menggunakan $\mathrm{MgCl}_{2} \quad\left(\mathrm{P}_{1}\right)$ lebih baik dibandingkan dengan menggunakan drying beads $\left(\mathrm{P}_{2}\right)$, dengan rata-rata kadar air dari perlakuan $\mathrm{MgCl}_{2}$ yaitu 2.684\%. Hal ini diduga karena $\mathrm{MgCl}_{2}$ pada saat itu belum mencapai titik jenuh, sedangkan perlakuan pengeringan menggunakan drying beads $\left(\mathrm{P}_{2}\right)$ sudah mencapai titik jenuh karena seluruh pori-porinya sudah terisi oleh $\mathrm{H}_{2} \mathrm{O}$ (Tabel 1.)

Tabel 1. Hasil Uji DMRT 5\% Perlakuan P terhadap Kadar Air Polen

\begin{tabular}{ccc}
\hline Perlakuan & Rata-rata & Notasi \\
\hline $\mathrm{P}_{2}$ & 2.684 & $\mathrm{~A}$ \\
$\mathrm{P}_{1}$ & 2.224 & $\mathrm{~B}$ \\
\hline
\end{tabular}

Keterangan : Huruf yang sama menunjukkan berbeda tidak nyata pada uji DMRT taraf 5\%

Dari hasil pengujian kadar air diperoleh rata-rata persentase kadar air yang disajikan pada Gambar 5.4 berikut. 
Dwi Rahmawati dan Prayitno, Viabilitas Polen Cabai Keriting (CK004) Pada Berbagai Kombinasi Pengeringan Dan Lama Penyimpanan

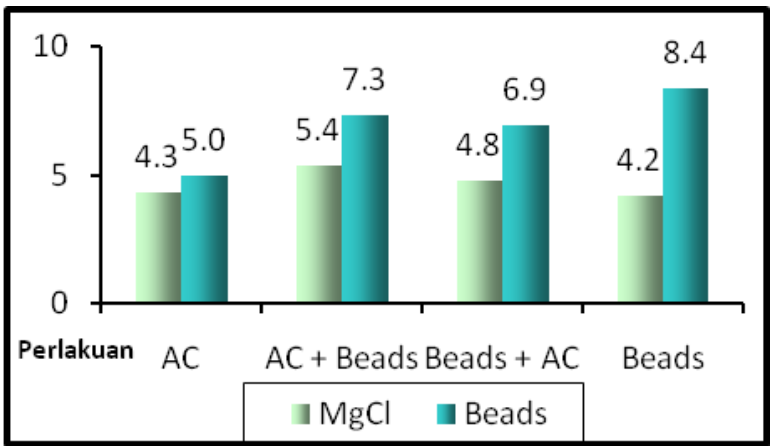

Gambar 1. Grafik Rata-rata Kadar Air Polen

Disamping itu, perbedaan tersebut diduga karena pada perlakuan pengeringan menggunakan $\mathrm{MgCl}_{2}$, kebutuhan $\mathrm{MgCl}_{2}$ yang digunakan tidak diukur sesuai dengan polen yang akan dikeringkan yaitu sebanyak 2 liter atau setara dengan $1,6 \mathrm{~kg}$ $\mathrm{MgCl}_{2}$ dan menghasilkan $\mathrm{RH}$ rata-rata 52,5\%. Sedangkan pada pengeringan menggunakan drying beads, kebutuhan drying beads diukur berdasarkan polen yang akan dikeringkan. Padahal dua bahan yang digunakan untuk pengeringan polen yaitu $\mathrm{MgCl}_{2}$ dan drying beads memiliki sifat yang sama yaitu higroskopis serta memiliki titik jenuh dimana kedua bahan adsorben itu sendiri tidak dapat menyerap air lagi. Hal itu terjadi ketika seluruh pori-pori sudah terisi oleh $\mathrm{H}_{2} \mathrm{O}$.

Mukherjee (2011) menyatakan bahwa $\mathrm{MgCl}_{2}$ bersifat higroskopis (dapat menyerap uap air dan udara) dan deliquescent (larut dalam air). $\mathrm{MgCl}_{2}$ padat akan menyerap kelembaban dari udara sampai larut sepenuhnya dan akan terus menyerap kelembaban sampai kesetimbangan tercapai. Sedangkan menurut Horticulture Collaborative Research Support Program (2012) Drying beads menghilangkan air dari udara dan menciptakan kelembaban yang sangat rendah di dalam wadah tertutup. Hal ini disebabkan karena drying beads mempunyai kemampuan menyerap air hingga titik jenuh tercapai yaitu kondisi dimana pori-pori drying beads telah terisi $\mathrm{H}_{2} \mathrm{O}$. Sebagaimana pernyataan Asbrouck and Taridno (2009) yaitu drying beads mampu menyerap air disekitarnya.

\section{Viabilitas Polen}

Viabilitas polen merupakan parameter penting, karena polen harus hidup dan mampu berkecambah setelah penyerbukan agar terjadi pembuahan. Ketersediaan polen dengan viabilitas yang tinggi merupakan salah satu komponen yang menentukan keberhasilan persilangan tanaman (Widiastuti dan Palupi, 2008). Menurut Galleta dalam Warid (1983) metode pengecambahan polen secara in vitro merupakan metode uji viabilitas polen yang dianggap paling baik.
Periode viabilitas polen merupakan periode polen dapat berkecambah dan dapat digunakan untuk penyerbukan. Viabilitas polen ditetapkan berdasarkan persentase perkecambahan polen yang dihitung dari jumlah polen yang berkecambah pada media pengecambahan polen. Suhu rata-rata ruangan pengecambahan polen berkisar antara 28 $32{ }^{\circ} \mathrm{C}$. Tidak semua polen dapat berkecambah dan membentuk tabung polen yang memanjang secara normal. Polen yang viabel adalah polen yang berhasil membentuk tabung polen (berkecambah) minimal sepanjang diameter polen (Gambar 1 a). Polen yang tidak viabel adalah polen yang tidak berkecambah, pecah, ataupun yang memiliki panjang tabung polen kurang dari diameter polen (Gambar 1 b).

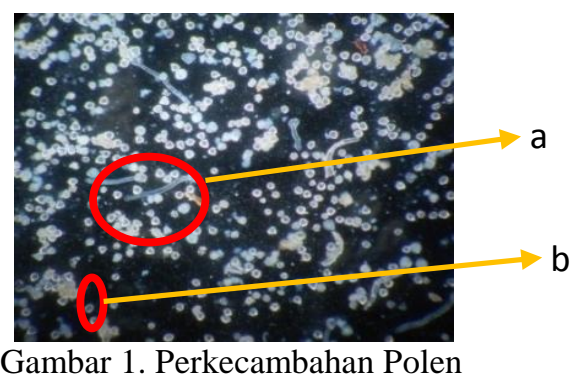

Polen merupakan jaringan hidup yang dapat mengalami kemunduran dan kematian. Daya hidup polen berbeda pada setiap spesies, dari beberapa jam, beberapa bulan, hingga beberapa tahun. Lama simpan polen dapat ditingkatkan dengan mengendalikan faktor-faktor yang mempengaruhi viabilitasnya. Faktor ini mencakup cahaya, suhu, udara, dan kelembaban (Galetta, 1983). Umumnya polen dapat disimpan lebih lama dalam kondisi kering dan suhu rendah.

Hasil ANOVA menunjukkan bahwa baik secara bersama-sama maupun secara sendirisendiri, perlakuan kombinasi pengeringan anther dan pollen $(\mathrm{P})$ serta perlakuan lama penyimpanan (T) tidak memberikan pengaruh yang nyata.terhadap viabilitas polen. Polen yang telah dikeringkan dengan berbagai kombinasi metode pengeringan dan disimpan selama 6 minggu, Setelah diuji viabilitasnya masih menunjukkan hasil yang cukup bagus yaitu diatas standar minimal daya berkecambah polen berdasarkan ISO PT. Eeast West Seed Indonesia No.SP/07/FPR tanggal 9 Februari 2009 untuk semua krop yaitu $1 \%$. Demikian juga dengan viabilitas polen sebelum disimpan. Dari hasil pengamatan terlihat bahwa viabilitas polen sebelum disimpan memiliki daya kecambah antara $2.78-6.04 \%$, sedangkan setelah disimpan 6 minggu memiliki daya kecambah 1.58 $4.56 \%$. 
Kondisi ini diduga karena polen yang dihasilkan dari berbagai kombinasi pengeringan memiliki kadar air awal yang sesuai untuk penyimpanan yaitu antara $4.2-8.4 \%$. Menurut tingkat viabilitas polen juga dipengaruhi oleh metode penyimpanan yang digunakan. Secara umum metode penyimpanan jangka panjang dengan teknik kriopreservasi akan lebih baik dibandingkan metode penyimpanan jangka pendek dengan pendinginan (Tambunan dan Mariska, 2003). Sebaliknya, pada suhu kamar polen akan lebih cepat kehilangan viabilitasnya karena aktivitas fisiologi berlangsung lebih cepat dan banyak energi yang dilepaskan sehingga polen akan lebih cepat mengalami kerusakan dan hanya mampu bertahan dalam jangka waktu pendek (Barbour et al., 1987). Pada penelitian ini, polen hasil pengeringan dengan berbagai kombinasi metode pengeringan disimpan di ultrafreezer suhu $-80{ }^{\circ} \mathrm{C}$. Suhu yang rendah tersebut sangat penting untuk ketahanan polen sehingga dapat bertahan lama dan tidak akan rusak. Selain itu, respirasi yang terjadi akan berjalan lambat. Menurut Widiastuti dan Palupi (2008), kualitas polen selama penyimpanan berhubungan dengan perubahan fisiologi dan biokimia. Dalam kondisi suhu rendah aktivitas fisiologi polen dapat ditekan sehingga sumber energinya dapat disimpan lebih lama.

Penyimpanan pada suhu rendah tidak menyebabkan perubahan kandungan air polen, karena air tersebut terikat dan tidak membeku (Hanna dan Towill, 1995). Suhu rendah dapat memperpanjang viabilitas serbuk sari dengan penurunan daya berkecambah yang relatif kecil. Walt dan Littlejohn (1996) membuktikan bahwa viabilitas serbuk sari Protea yang disimpan dalam nitrogen cair $-196^{\circ} \mathrm{C}$ relatif konstan di atas $90 \%$ setelah 1 tahun, sementara pada suhu $-18^{\circ} \mathrm{C}$ penurunan daya berkecambah sekitar $25 \%$ setelah 1 tahun

\section{KESIMPULAN DAN SARAN}

\section{Kesimpulan}

Dari hasil pembahasan pada bab sebelumnya dapat disimpulkan:

1. Kombinasi pengeringan anther dan polen tidak berpengaruh nyata terhadap viabilitas polen tanaman cabai keriting CK-004 (Capsicum annuит L.)

2. Lama penyimpanan polen hasil pengeringan, yaitu 0 dan 6 minggu, tidak berpengaruh nyata terhadap viabilitas polen tanaman cabai keriting CK-004 (Capsicum annuum L.) roostika et al. (2004) dengan menurunnya kandungan air dalam jaringan atau bertambahnya tingkat dehidrasi jaringan maka pembentukan es yang berlebihan dapat dihindarkan ketika jaringan disimpan dalam suhu rendah. Disamping itu,

3. Tidak terdapat interaksi kombinasi pengeringan anther dan polen dengan lama penyimpanan terhadap viabilitas polen tanaman cabai keriting CK-004 (Capsicum annuum L.)

\section{Saran}

Perlu diadakan penelitian lebih lanjut mengenai uji viabilitas polen dengan menggunakan metode yang berbeda dan waktu penyimpanan yang lebih lama agar didapat hasil yang lebih baik

\section{DAFTAR PUSTAKA}

Barbour, M.G., J.H. Burk, dan W.D. Pitts. 1987. Terrestrial Plant Ecology. Available at: http:/www.Cababstractsplus.org/abstracts/A bstract.aspx $/ \mathrm{AcNo}=19810725893$ Januari 2009)

BPS. 2012. Produksi Cabai Besar, Bawang Merah dan Mangga tahun 2011. Berita Resmi Statistik. 2012. No.53/08/Th XV 1 Agustus 2012.

http://www.bps.go.id/brs_file/holti_0lagu12 .$p d f$ [ 30 September 2012]

Direktorat Jendral Hortikultura, 2012. Pedoman Umum Pelaksanaan Pengembangan Hortikultura Tahun 2012. Direktorat Jendral Hortikultura, Jakarta.

Ditjen Hortikultura . Direktorat Jendral Hortikultura. 2009. Konsumsi Per kapita Hortikultura. Ditjen Hortikultura, Kementrian Pertanian, Jakarta.

East West Seed Indonesia. 2009. Standard Daya Berkecambah Pollen Released. No. SP/O7/FPR. Jember

Hanifah, A. K. 2011.Rancangan Percobaan 1 dan Aplikasi. PT. Raja Grafindo Persumu, Jakarta.

Hanna W.W. and L.E. Towill. 1995. Long-term pollen storage. In: Janick, J. (ed) Plant Breeding Reviews, Vol. 13. New York: John Wiley and Sons.

Mukherjee, B. Magnesium Chloride Uses. http://www.buzzle.com/articles/magnesiumchloride-uses.html. [23 Juni 2012]

Tambunan, I. R. dan I. Mariska. 2003. Pemanfaatan Teknik Kriopreservasi dalam Penyimpanan Plasma Nutfah Tanaman. Buletin Plasma Nutfah Vol.9 No.2 Th.2003. 
Jurnal Ilmiah INOVASI, Vol.13 No.3 Hal. 212-216, September-Desember 2013, ISSN 1411-5549 